\title{
Influences of Dysphagia on the Prognosis of Chinese Elderly Inpatients: a Prospective Cohort Study
}

\author{
Zhangmin Meng \\ Department of Geriatrics, National Clinical Research Center for Geriatrics, West China Hospital, Sichuan University \\ Yulan Zhou \\ West China School of Nursing, Sichuan University \\ Xiao Shu \\ West China School of Nursing, Sichuan University \\ Zijing Yang \\ West China School of Nursing, Sichuan University \\ Qian Chen ( $\nabla$ chen_qian@scu.edu.cn ) \\ Department of Geriatrics, National Clinical Research Center for Geriatrics, West China Hospital, Sichuan University
}

\section{Research Article}

Keywords: Dysphagia, malnutrition, aspiration pneumonia, death, older inpatients

Posted Date: August 24th, 2021

DOI: https://doi.org/10.21203/rs.3.rs-757510/v1

License: (1) This work is licensed under a Creative Commons Attribution 4.0 International License. Read Full License 


\section{Abstract}

The increasing incidence of dysphagia may pose threats to the health of older patients. The aim of this study was to investigate the adverse influences of dysphagia on the prognosis of older Chinese inpatients. A total of 290 older inpatients with different swallowing functions were involved in this study through group sampling from the geriatric centre of a 3A-level hospital in China. Among them, 125 patients (43.1\%) had dysphagia at admission. Based on a cross-sectional investigation, a prospective cohort study was conducted to investigate the incidence of complications, readmission, and death during 6 months of follow-up. A total of 34 patients $(11.7 \%)$ died, and the remaining 256 patients (88.3\%) were investigated concerning their complications. There was a higher prevalence of death among the older patients with dysphagia ( $15.6 \%$ vs $7.9 \%, R R=2.361)$. In terms of complications, older patients with dysphagia were more likely to develop malnutrition $(29.8 \%$ vs $5.9 \%, \mathrm{RR}=6.747)$ and aspiration pneumonia $(34.6 \%$ vs $11.2 \%, \mathrm{RR}=$ 4.204). Furthermore, multi-factor analysis demonstrated that dysphagia was an independent predictor of malnutrition and aspiration pneumonia but not an independent predictor of death. In conclusion, dysphagia was proven to be an independent predictor of a poor outcome of Chinese elderly inpatients. Specific clinical management and nursing interventions are recommended to prevent the potential adverse influences of dysphagia.

\section{Introduction}

With the growth of the older population in China, the incidence of geriatric syndromes that are harmful to health and life safety is continuously increasing, such as pressure sores and dysphagia [1, 2]. For example, by investigating 4038 elderly patients, Leder and Suiter [3] demonstrated that $37.7 \%$ of patients over 60 years old have dysphagia.

Dysphagia refers to a disorder of food or liquid transportation from the mouth to the stomach $[2,4,5]$. It can cause various complications, such as aspiration pneumonia, malnutrition, and even asphyxia [6]. In recent years, increasing attention has been given to dysphagia in elderly patients due to the necessity of avoiding these adverse outcomes.

Aspiration pneumonia is reported to be one of the most common complications of dysphagia [7]. For instance, a Singapore follow-up study [8] showed that dysphagia increased the incidence of chest infection. However, other simultaneous factors, such as food reflux from the stomach and saliva containing pathogenic bacteria, may also lead to aspiration pneumonia $[9,10]$. Further exploration is needed to determine whether dysphagia is an independent risk factor for aspiration pneumonia.

In terms of nutrition, dysphagia can lead to malnutrition by affecting the normal diet and nutritional intake of patients [11], especially when choking or coughing occurs. Patients with neurological impairment, masticatory weakness, sensory abnormality, or visual impairment may have serious difficulty during feeding. Dysphagia is also related to dehydration, when fluid aspiration occurs in patients with dysphagia and they are unable to drink or avoid doing so out of fear of choking and coughing [11, 12].

Moreover, it was reported that patients with dysphagia at admission had a higher mortality after a 3-month follow-up, and the mortality of stroke patients with dysphagia was $3-5$ times higher than those with normal swallowing functions [13, 14]. This is possibly associated with microbial translocation in the oropharynx and reduced systemic resistance $[11,15]$.

As mentioned above, many cross-sectional/retrospective studies have indicated that dysphagia can increase the risk of aspiration pneumonia, malnutrition, and even death in elderly patients $[16,17]$. However, these studies were mainly focused on stroke patients, and prospective cohort studies on the long-term adverse influences of dysphagia are lacking. Therefore, this prospective cohort study aimed to refine the current understanding of the impacts of dysphagia on the prognosis of older Chinese inpatients.

\section{Methods}

\subsection{Subjects}

A cross-sectional survey was conducted through convenience sampling of elderly inpatients in four geriatric wards (62 beds in each ward) of a teaching hospital in China from December 2018 to January 2019. Subsequently, a six-month follow-up survey was conducted from June 2019 to July 2019.

Inclusion criteria: inpatients aged 60 and above. The exclusion criteria were as follows: (1) patients in critical condition who needed to be rescued at any time; (2) patients who were forbidden to drink or eat by doctors; (3) patients who were clinically diagnosed with 
dementia (middle or late-onset) and could not be evaluated concerning their swallowing function; and (4) patients with serious mental diseases.

\subsection{Tools and content}

\subsubsection{General information}

Age, gender, marital status, and education level were investigated.

\subsubsection{Health function status}

(1) Comorbidity: the Charlson comorbidity index (CCl) was used. It consists of 19 items: diabetes mellitus (diabetic complications), congestive heart failure, peripheral artery disease, chronic lung disease, moderate or severe liver disease, hemiplegia, kidney disease, leukaemia, lymphoma, tumour metastasis and AIDS. Each of the items is weighted according to its impact on mortality [18].

(2) Disease severity: the Acute Physiology and Chronic Health Evaluation II (APACHE II) was used. This tool aims to comprehensively assess acute physiology, age and chronic health status. The final score is the sum of the three subscores. The higher it is, the more serious the disease [19].

(3) Cognitive function: The short portable mental status questionnaire (SPMSQ) was used [20, 21]. It concerns orientation, personal history, recent memory and computational power. The cognitive function level of the subject was assessed according to educational background (primary school, junior high school, senior high school and above). Furthermore, those clinically diagnosed with Alzheimer's disease ,or those with severe cognitive impairment written in the electronic medical record and unable to be evaluated by the scale were directly judged as having severe cognitive dysfunction.

(4) Ability of daily living: The Barthel Index (BI) was used [22], which is comprised of 10 items with a total score range of 0-100. It is classified into five levels: self-care (100 points), mild disorder (75-95 points), moderate disorder (50-70 points), severe disorder (2545 points), and extremely severe disorder (0-20 points).

(5) Swallowing function evaluation: the Kubota water swallow test was used [23]. The time required for patients to swallow $30 \mathrm{ml}$ water taken by mouth was recorded. The test was carried out once to record the shortest time and the occurrence of choking and coughing. This test has been widely used nationwide with good reliability and validity. If the result of this test is positive, the patient would undergo the standardized swallowing assessment. Patients who need gastric tube feeding were directly judged as dysphagia.

Standardized swallowing assessment (SSA): the SSA includes three parts: clinical examination, a $5 \mathrm{ml}$ water swallow test 3 times, and a $60 \mathrm{ml}$ water swallow test [24]. Difficulty swallowing is observed during the test. The final score ranges from 18 to 46 . The higher the score is, the more pronounced the dysphagia is. Patients whose score was $\geq 19$ were considered to have dysphagia.

In this study, people with a score $<22$ were tested again at an interval of 20 minutes. If the two scores were identically 18 or identically $\geq 19$, no more tests were implemented. If one score was $>18$ and another score was 18 , a third test was implemented after another 20 minutes. If the third score was $>18$, the patient was considered to have dysphagia.

The final determination of dysphagia was based on the positive results of both the Kubota water swallow test and the SSA. Moreover, dysphagia was directly determined if the patient was ordered to use nasogastric tubes by doctors.

\subsubsection{Prognosis}

Complications (malnutrition and aspiration pneumonia), readmission, and death were investigated.

\subsubsection{Malnutrition}

The Mini Nutritional Assessment Short Form (MNA-SF) was used to assess the nutritional status of the subjects [25]. The simplified MNA-SF scale includes six indexes: decreased food intake (3 months), weight loss (3 months), occurrence of stress or acute disease (3 months), mobility, neuropsychiatric disease, and body mass index (if the body mass index cannot be measured, the calf circumference is measured instead). The total score ranges from 0 to 14 . A total score of $<8$ indicates malnutrition.

\subsubsection{Aspiration pneumonia}


Aspiration pneumonia was judged according to the doctor's clinical diagnosis. If the type of pneumonia was not indicated in the medical record, it was judged by 2 deputy chief doctors with expertise in elderly respiration. The following indicators were necessary for diagnosis: history of aspiration, chest X-ray showing pulmonary fibrosis (or increased infiltration) or moist rales on chest

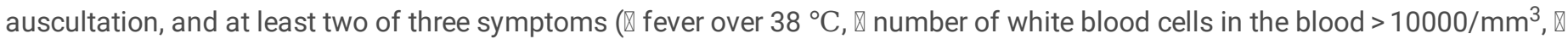
decreased content of oxygen in the blood [10]).

\subsubsection{Death}

The mortality of all of the patients by the end of the 6-month follow-up was investigated.

\subsubsection{Readmission}

The readmission rate (into hospitals, rehabilitation institutions or therapeutic nursing homes) of the live patients over the 6-month follow-up was investigated.

\subsection{Data collection}

The baseline data of inpatients were collected by investigators (nurse specialists from the geriatric centre who had been specially trained). Cognitive function and swallowing function were assessed within 24 hours after admission. Other demographic data were provided by the patients or their caregivers. Disease information and biochemical tests were collected from the electronic medical records. The investigators conducted a comprehensive inspection of the questionnaire immediately after collection to check the accuracy and completeness. Reverification was implemented if there was any doubt, error, or missing item. Furthermore, the investigators cross-checked each other. One-third of the questionnaires were randomly checked for accuracy by the authors themselves.

For the follow-up survey, the relevant data were collected by the investigators face to face when patients participated in the health education classes organized by the ward or returned for further consultation. The patients who could not be followed up as scheduled were investigated through telephone. Fourteen nurse specialists were each responsible following up 25-30 patients.

The data of the inpatients who died in the hospital were collected through electronic medical records, whereas the data of those who died elsewhere were collected through their relatives or friends.

\subsection{Investigation procedures}

The investigation procedures are shown in Fig. 1.

\subsection{Statistical analysis}

All of the data were input and managed through Excel 2016 and analysed using SPSS 18.0. Based on the type and distribution of the data, different methods were used for the statistical descriptions and statistical inferences.

Frequency and percentage were calculated for descriptions of counting data, and percentile spacing was calculated for descriptions of skewed data. For statistical inferences, the chi-square test was used for counting data, and binary logistic stepwise regression analysis was used for multivariate analysis. A two-tailed $p$ value of $<0.05$ indicated a statistically significant difference.

\subsection{Ethical considerations}

This study was approved by the clinical trial and biomedical ethics committee of the hospital and was conducted in accordance with the principles of the Declaration of Helsinki. Initially, the investigators carefully introduced the relevant information to the subjects. The subjects participated voluntarily and signed a written informed consent form. Moreover, because of traditional Chinese culture, family members tended to be reluctant to talk about deceased relatives. The investigators were required to demonstrate full respect and collect only the minimum required information.

\section{Results}

\subsection{General information of the elderly patients}


A total of 290 elderly patients were successfully followed up for 6 months. Among them, 34 elderly patients died, accounting for $11.7 \%$, and 125 had dysphagia, accounting for $43.1 \%$. The features of the 290 elderly patients were as follows: aged $\geq 80$ years $(66.2 \%)$, male (70.3\%), receiving public health care (68.6\%), having a spouse $(70.3 \%)$, living with a spouse $(60.7 \%)$, monthly income of 3,000 yuan and above (79.3\%), and having a middle school education or above (87.2\%). Their general information is shown in Table 1. Furthermore, the age, CCl, APACHE II, and BI of the 290 elderly inpatients were nonnormally distributed (Table S1).

Table 1

General information of the elderly inpatients involved in this study $(n=290)$

\begin{tabular}{|c|c|c|c|c|c|c|c|}
\hline Items & & $\mathrm{n}$ & $\%$ & Items & & $\mathbf{n}$ & $\%$ \\
\hline \multirow[t]{3}{*}{ Age (years old) } & $<70$ & 47 & 16.2 & \multirow[t]{2}{*}{ Marriage } & Married & 204 & 70.3 \\
\hline & $70 \sim 80$ & 51 & 17.6 & & Unmarried & 86 & 29.7 \\
\hline & $\geq 80$ & 192 & 66.2 & \multirow[t]{3}{*}{ Educational level } & Primary school and below & 37 & 12.8 \\
\hline \multirow[t]{2}{*}{ Gender } & Male & 204 & 70.3 & & Middle school & 134 & 46.2 \\
\hline & Female & 86 & 29.7 & & University and above & 119 & 41.0 \\
\hline
\end{tabular}

Table S1

Non-normal distribution of the relevant measurement data of the elderly inpatients $(n=290)$

\begin{tabular}{|llll|}
\hline Items & $\mathbf{P 2 5}$ & $\mathbf{P 5 0}$ & $\mathbf{P 7 5}$ \\
\hline Age & 74 & 82 & 86 \\
\hline CCI & 1.00 & 2.00 & 3.00 \\
\hline APACHE II & 7.00 & 11.00 & 14.00 \\
\hline BI & 50 & 80 & 100 \\
\hline
\end{tabular}

\subsection{Univariate analysis of the incidence of dysphagia}

A chi-square test based on the cross-sectional investigation at admission was performed. The incidence of dysphagia was higher among the elderly patients who had the following characteristics (Table 2): advanced age $(p<0.001)$, dementia $(p<0.001)$, stroke $(p=$ $0.001)$, Parkinson's disease $(p=0.001)$, dental masticatory disorder $(p<0.05)$, obstructive pulmonary disease $(p<0.001)$, a history of aspiration pneumonia $(p<0.05)$, a relatively high CCI score $(p<0.001)$, a relatively high APACHE II score $(p<0.001)$, daily life dysfunction $(p<0.001)$, and cognitive dysfunction $(p<0.001)$. 
Table 2

Univariate analysis of the incidence of dysphagia in the elderly inpatients $(n=290)$

\begin{tabular}{|c|c|c|c|c|c|c|c|c|c|c|c|c|}
\hline \multirow[t]{2}{*}{ Items } & & \multicolumn{2}{|c|}{ Total } & \multicolumn{2}{|c|}{$\begin{array}{l}\text { Normal } \\
\text { swallow } \\
(n=165)\end{array}$} & \multicolumn{2}{|c|}{$\begin{array}{l}\text { Dysphagia } \\
(n=125)\end{array}$} & \multirow[t]{2}{*}{$\otimes 2$} & \multirow[t]{2}{*}{$p$} & \multirow[t]{2}{*}{$\begin{array}{l}\text { OR } \\
\text { value }\end{array}$} & \multicolumn{2}{|l|}{$95 \% \mathrm{Cl}$} \\
\hline & & $\mathrm{n}$ & $\%$ & $\mathrm{n}$ & $\%$ & $\mathrm{n}$ & $\%$ & & & & $\begin{array}{l}\text { Lower } \\
\text { limit }\end{array}$ & $\begin{array}{l}\text { Upper } \\
\text { limit }\end{array}$ \\
\hline \multirow[t]{3}{*}{ Age } & $<70$ & 47 & 16.2 & 38 & 80.9 & 9 & 19.1 & & & & & \\
\hline & $70 \sim 80$ & 51 & 17.6 & 36 & 70.6 & 15 & 29.4 & & & & & \\
\hline & $\geq 80$ & 192 & 66.2 & 91 & 47.4 & 101 & 52.6 & 21.960 & 0.000 & & & \\
\hline \multirow[t]{2}{*}{ Gender } & Male & 202 & 69.7 & 113 & 55.4 & 91 & 44.6 & & 0.426 & & & \\
\hline & Female & 88 & 30.3 & 52 & 60.5 & 34 & 39.5 & & & & & \\
\hline \multirow[t]{2}{*}{ Stroke } & $x$ & 238 & 82.1 & 146 & 61.3 & 92 & 38.7 & & & & & \\
\hline & $\sqrt{ }$ & 52 & 17.9 & 19 & 36.5 & 33 & 63.5 & 10.708 & 0.001 & 2.756 & 1.470 & 4.985 \\
\hline \multirow{2}{*}{$\begin{array}{l}\text { Alzheimer's } \\
\text { disease }\end{array}$} & $x$ & 261 & 90.0 & 159 & 60.9 & 102 & 39.1 & & & & & \\
\hline & $\sqrt{ }$ & 29 & 10.0 & 6 & 20.7 & 23 & 79.3 & 17.224 & 0.000 & 5.975 & 2.361 & 14.430 \\
\hline \multirow{2}{*}{$\begin{array}{l}\text { Parkinson's } \\
\text { disease }\end{array}$} & $x$ & 268 & 92.4 & 160 & 59.7 & 108 & 40.3 & & & & & \\
\hline & $\sqrt{ }$ & 22 & 7.6 & 5 & 22.7 & 17 & 77.3 & 11.333 & 0.001 & 5.037 & 1.822 & 12.710 \\
\hline \multirow{2}{*}{$\begin{array}{l}\text { Other central } \\
\text { nervous } \\
\text { degeneration } \\
\text { disease }\end{array}$} & $x$ & 282 & 97.2 & 163 & 57.8 & 119 & 42.2 & & & & & \\
\hline & $\sqrt{ }$ & 8 & 2.8 & 2 & 25.0 & 6 & 75.0 & & 0.079 & & & \\
\hline \multirow{2}{*}{$\begin{array}{l}\text { Neuromuscular } \\
\text { disease }\end{array}$} & $x$ & 284 & 97.9 & 161 & 56.7 & 123 & 43.3 & & 0.702 & & & \\
\hline & $\sqrt{ }$ & 6 & 2.1 & 4 & 66.7 & 2 & 33.3 & & & & & \\
\hline \multirow{2}{*}{$\begin{array}{l}\text { Dental } \\
\text { masticatory } \\
\text { disorder }\end{array}$} & $x$ & 280 & 96.6 & 163 & 58.2 & 117 & 41.8 & & & & & \\
\hline & $\sqrt{ }$ & 10 & 3.4 & 2 & 20.0 & 8 & 80.0 & 5.749 & 0.017 & 5.573 & 1.332 & 26.34 \\
\hline \multirow{2}{*}{$\begin{array}{l}\text { Oropharyngeal } \\
\text { tumors }\end{array}$} & $x$ & 289 & 99.7 & 164 & 56.7 & 125 & 43.3 & & 1.000 & & & \\
\hline & $\sqrt{ }$ & 1 & .3 & 1 & 100.0 & 0 & 0.0 & & & & & \\
\hline \multirow{2}{*}{$\begin{array}{l}\text { Head and neck } \\
\text { injury }\end{array}$} & $x$ & 286 & 98.6 & 164 & 57.3 & 122 & 42.7 & & & & & \\
\hline & $\sqrt{ }$ & 4 & 1.4 & 1 & 25.0 & 3 & 75.0 & & 0.318 & & & \\
\hline \multirow{2}{*}{$\begin{array}{l}\text { Head and neck } \\
\text { tumors }\end{array}$} & $x$ & 288 & 99.3 & 164 & 56.9 & 124 & 43.1 & & & & & \\
\hline & $\sqrt{ }$ & 2 & .7 & 1 & 50.0 & 1 & 50.0 & & 1.000 & & & \\
\hline \multirow{2}{*}{$\begin{array}{l}\text { Gastroesophageal } \\
\text { reflux }\end{array}$} & $x$ & 287 & 99.0 & 163 & 56.8 & 124 & 43.2 & & 1.000 & & & \\
\hline & $\sqrt{ }$ & 3 & 1.0 & 2 & 66.7 & 1 & 33.3 & & & & & \\
\hline \multirow{2}{*}{$\begin{array}{l}\text { Esophageal } \\
\text { cancer }^{*}\end{array}$} & $x$ & 287 & 99.0 & 165 & 57.5 & 122 & 42.5 & & & & & \\
\hline & $\sqrt{ }$ & 3 & 1.0 & 0 & 0.0 & 3 & 100.0 & & 0.079 & & & \\
\hline \multirow{2}{*}{$\begin{array}{l}\text { Other esophageal } \\
\text { diseases }\end{array}$} & $x$ & 289 & 99.7 & 164 & 56.7 & 125 & 43.3 & & 1.000 & & & \\
\hline & $\sqrt{ }$ & 1 & .3 & 1 & 100.0 & 0 & 0.0 & & & & & \\
\hline \multirow{2}{*}{$\begin{array}{l}\text { Chronic } \\
\text { obstructive } \\
\text { pulmonary } \\
\text { disease }\end{array}$} & $x$ & 229 & 79.0 & 143 & 62.4 & 86 & 37.6 & & & & & \\
\hline & $\sqrt{ }$ & 61 & 21.0 & 22 & 36.1 & 39 & 63.9 & 13.668 & 0.000 & 2.948 & 1.612 & 5.228 \\
\hline
\end{tabular}




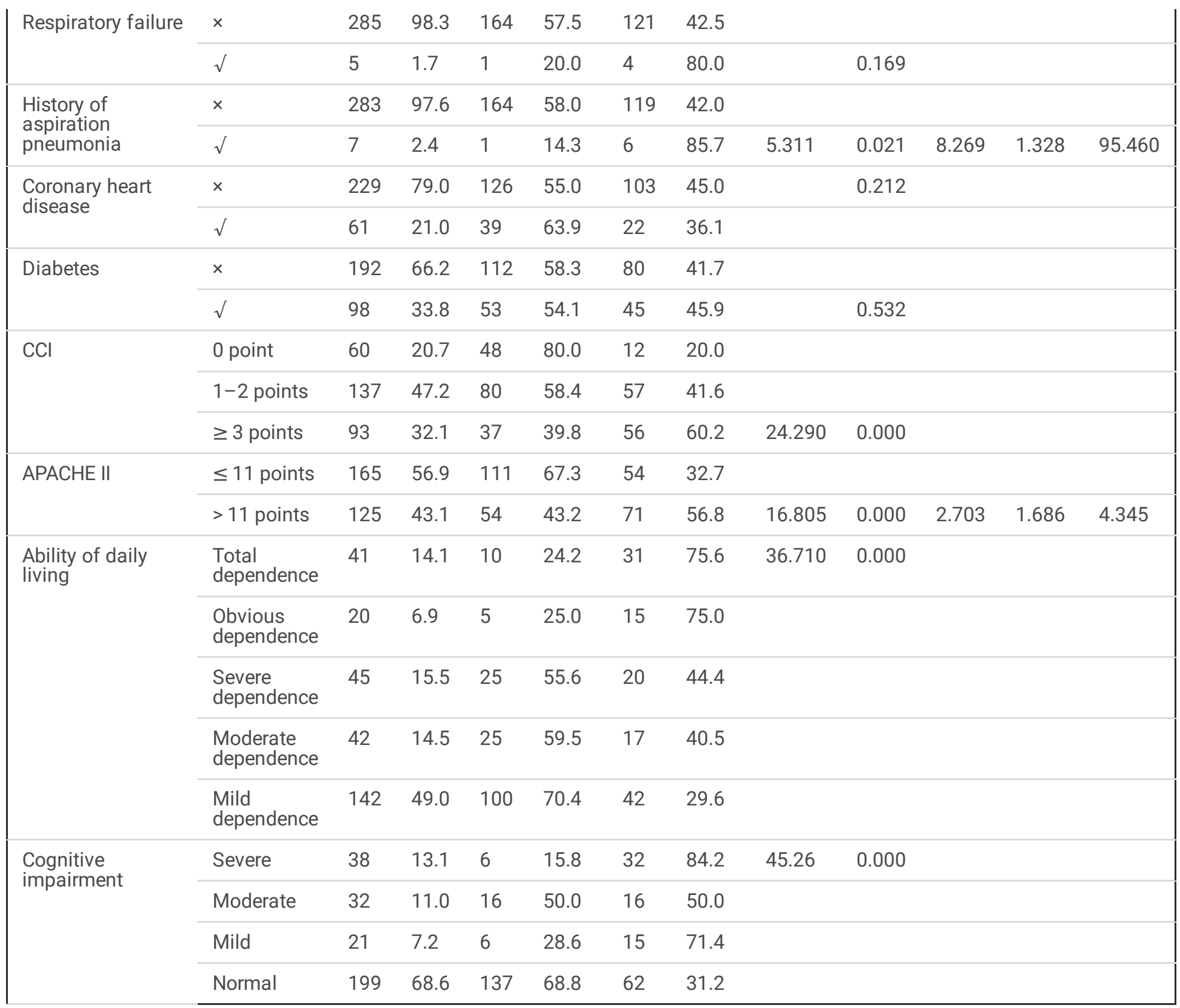

\subsection{Analysis of the effect of dysphagia on death}

A total of 290 elderly inpatients were followed up for 6 months, and 34 of them died (11.7\%). Elderly patients with dysphagia were found to have a higher mortality risk than those with normal swallowing function ( $R R=2.361,95 \% \mathrm{Cl}=1.132-4.925, \mathrm{Table} 3$ ).

However, according to the logistic regression analysis, dysphagia was not an independent predictor of death.

Table 3

Effect of dysphagia on the mortality of the elderly patients $(n=290)$

\begin{tabular}{|c|c|c|c|c|c|c|c|c|c|c|c|}
\hline \multirow[t]{2}{*}{ Death } & \multicolumn{2}{|c|}{ Total } & \multicolumn{2}{|c|}{ Normal swallow } & \multicolumn{2}{|c|}{ Dysphagia } & \multirow[t]{2}{*}{$\$ 2$} & \multirow[t]{2}{*}{$p$} & \multirow[t]{2}{*}{ RR value } & \multicolumn{2}{|l|}{$95 \% \mathrm{Cl}$} \\
\hline & $\mathrm{n}$ & $\%$ & $\mathbf{n}$ & $\%$ & $\mathrm{n}$ & $\%$ & & & & Lower limit & Upper limit \\
\hline$x$ & 256 & 88.3 & 152 & 92.1 & 104 & 83.2 & & & & & \\
\hline$\sqrt{ }$ & 34 & 11.7 & 13 & 7.9 & 21 & 16.8 & 5.469 & 0.019 & 2.361 & 1.132 & 4.925 \\
\hline
\end{tabular}

\subsection{Analysis of the effect of dysphagia on complications}


Over the 6-month follow-up, among the 256 elderly patients(Table 4), 40 developed malnutrition (MNA-SF < 8), accounting for $15.6 \%$, and 53 developed aspiration pneumonia, accounting for $20.7 \%$. Logistics regression analysis of malnutrition and aspiration pneumonia in the elderly inpatients is shown in Table 5.

Table 4

The incidence of malnutrition and aspiration pneumonia in the elderly inpatients $(n=256)$

\begin{tabular}{|c|c|c|c|c|c|c|c|c|c|c|c|}
\hline \multirow[t]{2}{*}{ Items } & \multicolumn{2}{|c|}{ Total } & \multicolumn{2}{|c|}{$\begin{array}{l}\text { Normal } \\
\text { swallow }\end{array}$} & \multicolumn{2}{|c|}{ Dysphagia } & \multirow[t]{2}{*}{$\$ 2$} & \multirow[t]{2}{*}{$p$} & \multirow[t]{2}{*}{$\begin{array}{l}\text { RR } \\
\text { value }\end{array}$} & \multicolumn{2}{|l|}{$95 \% \mathrm{Cl}$} \\
\hline & $n$ & $\%$ & $\mathbf{n}$ & $\%$ & $\mathrm{n}$ & $\%$ & & & & $\begin{array}{l}\text { Lower } \\
\text { limit }\end{array}$ & $\begin{array}{l}\text { Upper } \\
\text { limit }\end{array}$ \\
\hline Normal & 216 & 84.4 & 143 & 94.1 & 73 & 70.2 & 26.725 & 0.001 & 6.747 & 3.050 & 14.952 \\
\hline Malnutrition & 40 & 15.6 & 9 & 5.9 & 31 & 29.8 & & & & & \\
\hline Normal & 203 & 79.3 & 135 & 88.8 & 68 & 65.4 & 20.651 & 0.001 & 4.204 & 2.203 & 8.023 \\
\hline $\begin{array}{l}\text { Aspiration } \\
\text { pneumonia }\end{array}$ & 53 & 20.7 & 17 & 11.2 & 36 & 34.6 & & & & & \\
\hline
\end{tabular}

Table 5

Logistics regression analysis of malnutrition and aspiration pneumonia in the elderly inpatients $(n=256)$

\begin{tabular}{|c|c|c|c|c|c|c|c|c|}
\hline & \multirow[t]{2}{*}{ Items } & \multirow[t]{2}{*}{ B } & \multirow[t]{2}{*}{ S.E } & \multirow[t]{2}{*}{ Wals } & \multirow[t]{2}{*}{ Sig. } & \multirow[t]{2}{*}{$\operatorname{Exp}(B)$} & \multicolumn{2}{|l|}{$95 \% \mathrm{Cl}$} \\
\hline & & & & & & & Lower limit & Upper limit \\
\hline \multirow[t]{3}{*}{ malnutrition } & Disease severity & -.974 & .383 & 6.455 & .011 & .378 & .178 & .800 \\
\hline & Dysphagia & -1.752 & .412 & 18.099 & .000 & .173 & .077 & .389 \\
\hline & Constant & 4.165 & .685 & 37.008 & .000 & 64.390 & & \\
\hline \multirow{4}{*}{$\begin{array}{l}\text { aspiration } \\
\text { pneumonia }\end{array}$} & Age & .626 & .295 & 4.500 & .034 & 1.871 & 1.049 & 3.337 \\
\hline & Dysphagia & 1.027 & .353 & 8.482 & .004 & 2.793 & 1.399 & 5.576 \\
\hline & Alzheimer's disease & 1.842 & .505 & 13.279 & .000 & 6.309 & 2.343 & 16.990 \\
\hline & Constant & -3.726 & .815 & 20.897 & .000 & .024 & & \\
\hline
\end{tabular}

\subsubsection{Malnutrition}

The incidence of malnutrition in elderly patients with dysphagia was higher than that in those with normal swallowing function (RR = $6.747,95 \% \mathrm{Cl}=3.050-14.952$, Table 4). Factors influencing malnutrition screened out through univariate analysis $(p<0.05)$ included age, dysphagia, dementia, dental masticatory disorder, ability of daily living, and disease severity. Based on these factors, multivariate analysis was performed through stepwise regression, and dysphagia was found to be an independent risk factor of malnutrition (RR $=0.173,95 \% \mathrm{Cl}=0.077-0.389$, Table 5).

\subsubsection{Aspiration pneumonia}

The incidence of aspiration pneumonia was higher in patients with dysphagia than in those with normal swallowing function (RR = $4.204,95 \%, \mathrm{Cl}=2.203-8.023$, Table 4). Factors influencing aspiration pneumonia screened out through univariate analysis $(p<0.05)$ included age, dysphagia, Alzheimer's disease, chronic obstructive pulmonary disease, disease severity, comorbidity, and ability of daily living. Based on these factors, multivariate analysis was performed through stepwise regression, and dysphagia was found to be an independent risk factor of aspiration pneumonia $(\mathrm{RR}=2.793,95 \% \mathrm{Cl}=1.399-5.576$, Table 5).

\subsection{Analysis of the effect of dysphagia on readmission}


Among the 256 elderly inpatients who survived to the end of follow-up, 86 were re-admitted, accounting for $33.6 \%$. There was no significant difference in the readmission rate between elderly patients with dysphagia and those with normal swallowing function ( $p>$ 0.05 , Table S2).

Table S2

Effect of dysphagia on the readmission rate of the elderly patients $(n=256)$

\begin{tabular}{|c|c|c|c|c|c|c|c|c|c|c|c|}
\hline \multirow[t]{2}{*}{ Readmission } & \multicolumn{2}{|c|}{ Total } & \multicolumn{2}{|c|}{ Normal swollow } & \multicolumn{2}{|c|}{ Dysphagia } & \multirow[t]{2}{*}{$\$ 2$} & \multirow[t]{2}{*}{$P$} & \multirow[t]{2}{*}{ RR value } & \multicolumn{2}{|l|}{$95 \% \mathrm{Cl}$} \\
\hline & $\mathrm{n}$ & $\%$ & $n$ & $\%$ & $\mathrm{n}$ & $\%$ & & & & Lower limit & Upper limit \\
\hline$x$ & 170 & 66.4 & 97 & 63.8 & 73 & 70.2 & 1.125 & 0.289 & 1.214 & 0.852 & 1.756 \\
\hline$\sqrt{ }$ & 86 & 33.6 & 55 & 36.2 & 31 & 29.8 & & & & & \\
\hline
\end{tabular}

\section{Discussion}

\subsection{Dysphagia and death}

According to the literature, it is generally accepted that dysphagia is one of the indicators of disease severity in older patients, but it may not be a direct risk factor of mortality [11]. In this study, it was found that the mortality of older patients with dysphagia after 6 months was higher than that of patients with normal swallowing function ( $R R=2.361,95 \% \mathrm{Cl}=1.132-4.925$, Table 3$)$, but dysphagia was not an independent predictor of death. These results are consistent with previous studies [11].

The relationship between dysphagia and death can be analysed through the following two points. First, older inpatients with dysphagia generally have a higher incidence of major diseases, such as stroke, Alzheimer's disease and Parkinson's disease, as suggested by a previous cross-sectional investigation. These diseases can independently affect the mortality of older patients [2629]. In addition, elderly inpatients with dysphagia have a higher incidence of other complications, such as malnutrition and aspiration pneumonia. Malnutrition can lead to decreased health function and independently affect the rehabilitation and prognosis of elderly patients [30]. Aspiration pneumonia is also an independent predictor of death in elderly patients [2, 31].

In conclusion, dysphagia can be considered an indirect risk factor for death in older patients. It may be a concurrent symptom of independent predictors of death and may give rise to other independent predictors of death.

\subsection{Dysphagia and malnutrition/aspiration pneumonia}

In this study, the incidence of malnutrition in elderly patients with dysphagia was higher than that in those with normal swallowing function $(\mathrm{RR}=6.747,95 \% \mathrm{Cl}=3.050-14.952$, Table 4$)$, and dysphagia was an independent predictor of malnutrition $(\mathrm{RR}=0.173,95 \%$ $\mathrm{Cl}=0.077-0.389$, Table 5). This may be because older patients with dysphagia have less food intake to avoid choking and aspiration. In addition, since general nutrition interventions cannot effectively improve the nutritional status of older patients with dysphagia, comprehensive nutrition interventions and rehabilitation are needed [32,33]. However, caregivers tend to lack the relevant knowledge and fail to reasonably adjust the eating patterns of older patients after discharge, thus leading to further development of malnutrition $[34,35]$.

Furthermore, the incidence of aspiration pneumonia in older patients with dysphagia was higher than in those without dysphagia (RR $=4.204,95 \% \mathrm{Cl}=2.203-8.023$, Table 4). Our result is consistent with a previous meta-analysis [36]. The RR value in the current study was lower than in the meta-analysis [36], possibly because of the exclusion of acute stroke patients and critical patients in the current study.

Many studies have been conducted to explore the relationship between dysphagia and aspiration pneumonia. For example, Scannapieco et al. [37-40] proposed several possible mechanisms, including oral bacteria being inhaled into the lung tissue, respiratory pathogens surviving in the diseased oral cavity and being inhaled into the lung tissue, dysfunction of the nonspecific host defence mechanism, and cytokines derived from periodontitis affecting the respiratory epithelial cells.

\subsection{Guidance for nursing interventions}


Considering the adverse influences of dysphagia, specific nursing interventions are highly recommended [41-43]. Desirable intervention measures include (1) oral care (such as gargles and electric toothbrushing), (2) monitoring of nutritional status, (3) management of eating (such as the quality of food and food intake), (4) training of swallowing function, (5) management of artificial airways (such as nasogastric tubes), and (6) psychological nursing concerning the patient's anxiety, fear, and dependence.

\subsection{Limitations}

This study has certain limitations that should be addressed in future studies. (1) The subjects involved in this study were from only one geriatric centre. Multi-centre studies are desired in the future. (2) The follow-up duration of this study was 6 months, which should be further extended. (3) The specific time of death was not collected. (4) In this study, the identification of dysphagia was based on observational assessment. More objective and rigorous methods, such as fibrous endoscopy, should be used in future studies.

\section{Conclusion}

In conclusion, this study demonstrates that dysphagia is an independent predictor of malnutrition and aspiration pneumonia in older Chinese patients. Furthermore, the evaluation and management of dysphagia and relevant complications should be taken seriously in elderly patients, and effective nursing interventions should be applied to improve their prognosis.

\section{Declarations}

\section{Ethics approval and consent to participate}

This study was approved by the clinical trial and biomedical ethics committee of the hospital and was conducted in accordance with the principles of the Declaration of Helsinki. Initially, the investigators carefully introduced the relevant information to the subjects. The subjects participated voluntarily and signed a written informed consent form. Moreover, because of traditional Chinese culture, family members tended to be reluctant to talk about deceased relatives. The investigators were required to demonstrate full respect and collect only the minimum required information.

\section{Consent for publication}

Not applicable.

\section{Availability of data and material}

The datasets generated and/or analysed during the current study are available in the Baidu network disk 口https://pan.baidu.com/s/14kA8eWE9itqaL46370_QfA囚. And the extraction code is 97q2.

\section{Competing interests}

The authors declare that they have no competing interests.

\section{Funding}

This study is supported by Health Department of Sichuan Province (2015-106), Department of Science and Technology of Sichuan Province (2018SZ0247), and Sichuan University (C2020108344, C2020110744). The funders had no role in the design of the study or the interpretation of the findings.

\section{Authors' contributions}

$Z M$ and $Y Z$ contributed equally to this study. They completed the main study design $\llbracket$ data analysis and wrote the main manuscript text. XS and ZY prepared figures and helped complete data analysis. QC is the corresponding author, and guided and helped complete the whole article. All authors read and approved the final manuscript.

\section{Acknowledgements}

We are deeply appreciative of Dr. Liu Guanjian (Office of Clinical Diseases, Sichuan University) for statistical analysis guidance, and all the geriatric nurses that participated in this study (Department of Geriatrics, West China Hospital, Sichuan University). 
The authors declare no conflict of interest.

\section{References}

1. Di Pede C, Mantovani ME, Del Felice A, Masiero S: Dysphagia in the elderly: focus on rehabilitation strategies. Aging Clin Exp Res 2016, 28(4):607-617.

2. Ebihara S, Sekiya H, Miyagi M, Ebihara T, Okazaki T: Dysphagia, dystussia, and aspiration pneumonia in elderly people. $J$ Thorac Dis 2016, 8(3):632-639.

3. Leder SB, Suiter DM: An epidemiologic study on aging and dysphagia in the acute care hospitalized population: 2000-2007. Gerontology 2009, 55(6):714-718.

4. Giammarino C, Adams E, Moriarty C, Cristian A: Safety concerns and multidisciplinary management of the dysphagic patient. Phys Med Rehabil Clin N Am 2012, 23(2):335-342.

5. Okamoto N, Tomioka K, Saeki K, Iwamoto J, Morikawa M, Harano A, Kurumatani N: Relationship between swallowing problems and tooth loss in community-dwelling independent elderly adults: the Fujiwara-kyo study. Journal of the American Geriatrics Society 2012, 60(5):849-853.

6. Nogueira D, Reis E: Swallowing disorders in nursing home residents: how can the problem be explained? Clinical Interventions in Aging 2013, 8:221-227.

7. Dantas RO, Cassiani R, Santos C, Baddini-Martinez J: Oral and pharyngeal bolus transit in patients with chronic obstructive pulmonary disease. International Journal of Chronic Obstructive Pulmonary Disease 2015, 10(1):489-496.

8. Lee A, Sitoh YY, Lieu PK, Phua SY, Chin JJ: Swallowing impairment and feeding dependency in the hospitalised elderly. Ann Acad Med Singapore 1999, 28(3):371-376.

9. Funahara M, Soutome S, Hayashida S, Umeda M: An analysis of the factors affecting the number of bacteria in the saliva of elderly adults in need of care. International Journal of Gerontology 2018, 12(3):205-207.

10. Johnson ER, McKenzie SW, Sievers A: Aspiration pneumonia in stroke. Arch Phys Med Rehabil 1993, 74(9):973-976.

11. Altman KW, Yu GP, Schaefer SD: Consequence of dysphagia in the hospitalized patient: impact on prognosis and hospital resources. Arch Otolaryngol Head Neck Surg 2010, 136(8):784-789.

12. Madhavan A, LaGorio LA, Crary MA, DahI WJ, Carnaby GD: Prevalence of and risk factors for dysphagia in the community dwelling elderly: A systematic review. J Nutr Health Aging 2016, 20(8):806-815.

13. Horner J, Massey EW: Silent aspiration following stroke. Neurology 1988, 38(2):317-319.

14. Cohen DL, Roffe C, Beavan J, Blackett B, Fairfield CA, Hamdy S, Havard D, McFarlane M, McLauglin C, Randall M et al: Post-stroke dysphagia: A review and design considerations for future trials. Int J Stroke 2016, 11(4):399-411.

15. Maeshima S, Osawa A, Miyazaki Y, Seki Y, Miura C, Tazawa Y, Tanahashi N: Influence of dysphagia on short-term outcome in patients with acute stroke. Am J Phys Med Rehabil 2011, 90(4):316-320.

16. Gandolfi M, Smania N, Bisoffi G, Squaquara T, Zuccher P, Mazzucco S: Improving post-stroke dysphagia outcomes through a standardized and multidisciplinary protocol: an exploratory cohort study. Dysphagia 2014, 29(6):704-712.

17. Middleton S, McElduff P, Ward J, Grimshaw JM, Dale S, D'Este C, Drury P, Griffiths R, Cheung NW, Quinn C et al: Implementation of evidence-based treatment protocols to manage fever, hyperglycaemia, and swallowing dysfunction in acute stroke (QASC): a cluster randomised controlled trial. Lancet 2011, 378(9804):1699-1706.

18. Mnatzaganian G, Ryan P, Norman PE, Hiller JE: Accuracy of hospital morbidity data and the performance of comorbidity scores as predictors of mortality. Journal of Clinical Epidemiology 2012, 65(1):107-115.

19. Lee H, Lim C, Hong H, Ju J, Jeon YT, Hwang J-W, Park HP: Efficacy of the APACHE II score at ICU discharge in predicting post-ICU mortality and ICU readmission in critically ill surgical patients. Anaesthesia and Intensive Care 2015, 43(2):175-186.

20. COTTI A, CLERICI F: Cognitive impairment is a negative short-term and long-term prognostic factor in elderly patients with hip fracture. Eur J Phys Rehabil Med 2015, 51(6).

21. Lee $\mathrm{C}-\mathrm{H}$, Sun $\mathrm{T}-\mathrm{L}$, Jiang $\mathrm{BC}$, Choi $\mathrm{VH}$ : Using wearable accelerometers in a community service context to categorize falling behavior. Entropy 2016, 18(7):257. 
22. Galeoto G, Lauta A, Palumbo A, Castiglia S, Mollica R, Santilli V, Sacchetti M: The Barthel Index: Italian translation, adaptation and validation. Int J Neurol Neurother 2015, 2(1):1-7.

23. Chen PC, Chuang CH, Leong CP, Guo SE, Hsin YJ: Systematic review and meta-analysis of the diagnostic accuracy of the water swallow test for screening aspiration in stroke patients. Journal of Advanced Nursing 2016, 72(11):2575-2586.

24. Jiang J-L, Fu S-Y, Wang W-H, Ma Y-C: Validity and reliability of swallowing screening tools used by nurses for dysphagia: A systematic review. Tzu Chi Medical Journal 2016, 28(2):41-48.

25. Lozoya RM, Martínez-Alzamora N, Marín GC, Guirao-Goris SJ, Ferrer-Diego RM: Predictive ability of the Mini Nutritional Assessment Short Form (MNA-SF) in a free-living elderly population: a cross-sectional study. PeerJ 2017, 5(17):e3345.

26. Xue H, Sun Q, Liu L, Zhou L, Liang R, He R, Yu H: Risk factors of transition from mild cognitive impairment to Alzheimer's disease and death: A cohort study. Compr Psychiatry 2017, 78:91-97.

27. Scorza FA, Gadelha A, Ferraz HB, Finsterer J, Bressan RA: Beyond the neuropsychiatric horizon: Assessing the risk of sudden unexpected death in parkinson disease. J Am Med Dir Assoc 2017, 18(11):988.

28. Senoo K, An Y, Ogawa H, Lane DA, Wolff A, Shantsila E, Akao M, Lip GY: Stroke and death in elderly patients with atrial fibrillation in Japan compared with the United Kingdom. Heart 2016, 102(23):1878-1882.

29. Kumar S, Wagner CW, Frayne C, Zhu L, Selim M, Feng W, Schlaug G: Noninvasive brain stimulation may improve stroke-related dysphagia: a pilot study. Stroke 2011, 42(4):1035-1040.

30. Söderström L, Rosenblad A, Adolfsson ET, Bergkvist L: Malnutrition is associated with increased mortality in older adults regardless of the cause of death. British Journal of Nutrition 2017, 117(4):532-540.

31. Palacios-Ceña D, Hernández-Barrera V, López-de-Andrés A, Fernández-de-Las-Peñas C, Palacios-Ceña M, de Miguel-Díez J, Carrasco-Garrido P, Jiménez-García R: Time trends in incidence and outcomes of hospitalizations for aspiration pneumonia among elderly people in Spain (2003-2013). European Journal of Internal Medicine 2017, 38:61-67.

32. Maeda K, Akagi J: Treatment of sarcopenic dysphagia with rehabilitation and nutritional support: A comprehensive approach. $J$ Acad Nutr Diet 2016, 116(4):573-577.

33. Eglseer D, Halfens RJG, Schols J, Lohrmann C: Dysphagia in hospitalized older patients: Associated factors and nutritional interventions. J Nutr Health Aging 2018, 22(1):103-110.

34. Namasivayam-MacDonald AM, Shune SE: The Burden of dysphagia on family caregivers of the elderly: A systematic review. Geriatrics 2018, 3(2):30.

35. Tana C, Lauretani F, Ticinesi A, Gionti L, Nouvenne A, Prati B, Meschi T, Maggio M: Impact of nutritional status on caregiver burden of elderly outpatients. A cross-sectional study. Nutrients 2019, 11(2):281.

36. van der Maarel-Wierink CD, Vanobbergen JN, Bronkhorst EM, Schols JM, de Baat C: Meta-analysis of dysphagia and aspiration pneumonia in frail elders. $J$ Dent Res 2011, 90(12):1398-1404.

37. Scannapieco FA, Shay K: Oral health disparities in older adults: oral bacteria, inflammation, and aspiration pneumonia. Dent Clin North Am 2014, 58(4):771-782.

38. Scannapieco FA, Bush RB, Paju S: Associations between periodontal disease and risk for nosocomial bacterial pneumonia and chronic obstructive pulmonary disease. A systematic review. Annals of Periodontology 2003, 8(1):54-69.

39. Russell SL, Boylan RJ, Kaslick RS, Scannapieco FA, Katz RV: Respiratory pathogen colonization of the dental plaque of institutionalized elders. Spec Care Dentist 1999, 19(3):128-134.

40. Scannapieco FA, Cantos A: Oral inflammation and infection, and chronic medical diseases: implications for the elderly. Periodontology 2000 2016, 72(1):153-175.

41. Kojima A, Imoto Y, Osawa Y, Fujieda S: Predictor of rehabilitation outcome for dysphagia. Auris Nasus Larynx 2014, 41(3):294298.

42. Shen HC, Chen HF, Peng LN, Lin MH, Chen LK, Liang CK, Lo YK, Hwang SJ: Impact of nutritional status on long-term functional outcomes of post-acute stroke patients in Taiwan. Arch Gerontol Geriatr 2011, 53(2):e149-152.

43. Sura L, Madhavan A, Carnaby G, Crary MA: Dysphagia in the elderly: management and nutritional considerations. Clin Interv Aging 2012, 7:287-298.

\section{Figures}

Page $12 / 13$ 
812 patients were admitted into the four wards within two months

$$
\vdots
$$

722 patients met the inclusion

criteria

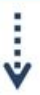

290 patients completed the

cross-sectional investigation

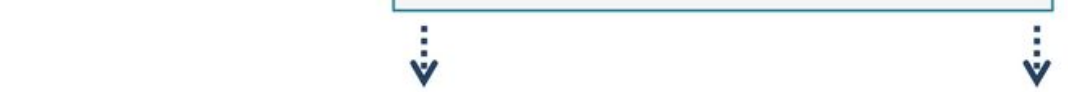

\section{5 patients had normal} swallow function
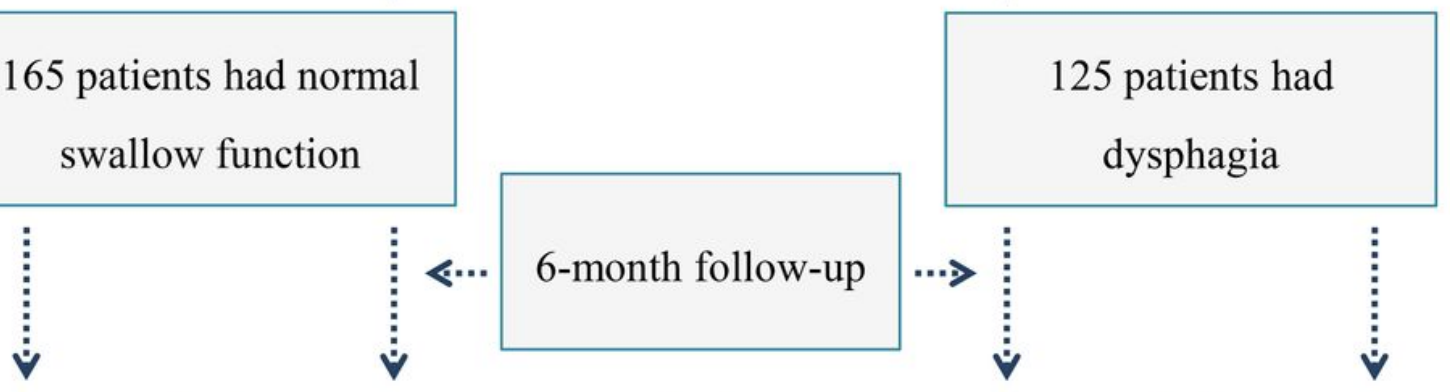

152 patients survived

13 patients died

104 patients survived

21 patients died

Figure 1

investigation procedures

\section{Supplementary Files}

This is a list of supplementary files associated with this preprint. Click to download.

- data.zip 